\title{
Play in the primary school classroom? - The experience of teachers supporting children's learning through a new pedagogy.
}

\begin{abstract}
.
In Scotland in recent years there has been growing interest in an approach to a more play based pedagogy commonly described as Active Learning. The research reported in this article is an exploration of moves towards creating an active play based learning environment in six Primary 1 classrooms in Scotland and is concerned with (i) the children's experiences in such a play based active learning environment in school and (ii) their teachers' perspectives on this pedagogical innovation and their roles in supporting the learners.

This study examined experiences and perspectives within and across each of the six childcentred and play-focused classes. The main findings suggest that the role of the teacher varies between what would be considered teacher-intensive and teacher initiated activities (Fisher,1996:55) Active’ or play based learning’ was interpreted differently by teachers; play in some classrooms was peripheral rather than integral to the learning process and curriculum-embedded.
\end{abstract}

\section{Key words}

Active learning; play; pedagogy; teacher activity; children’s engagement

\section{Introduction.}

This article describes a research project undertaken within the Learners, Learning and Teaching Network, which was part of Scotland's Applied Educational Research Scheme $(\mathrm{AERS})^{\mathrm{i}}$. The study was undertaken in response to the findings of an earlier Network study 
which looked at the ways teachers and children understood engagement in learning in the first year of both Primary and Secondary school (Stephen et al, 2008; 2009).

This earlier study found that teachers thought of engagement as participation in learning activities they selected and carried out in ways they expected. However, for children, engagement came from active involvement, autonomy and the opportunity for choice. The children were enthusiastic about tasks which were active and open ended such as Physical Education and where there was supervision at a distance from the adults. The prior study identified the need to explore the impact of Scotland's new Curriculum for Excellence (CfE) framework (Scottish Executive, 2004) and the national changes in curriculum design and delivery for children 3-18 in Scotland, in the context of the guidance on an Early Level for children 3-6, spanning preschool and the first class in primary school (Scottish Executive, 2007). The way in which teachers were challenged to provide a curriculum which offers children choice within the classroom, in response to the move towards 'active learning' or a play based curriculum, emerged as an issue for further investigation through the AERS Network (Stephen et al 2009).

\section{Context}

The new research project was therefore set in a changing policy context within local authorities in Scotland, which aimed to build on the recommendations emerging from CfE that there should be greater emphasis on active learning, described as planned purposeful play in the early years of schooling (Scottish Executive, 2007) and an understanding that children have agency and distinct preferences, and are primed to learn (David et al, 2003). Children in Scotland start formal schooling in the August nearest their 5th birthday, starting school between the age of 4 years 7 months and 5 years 5 months. They are among the youngest 
children in Europe to start school, and have had to cope with a classroom environment and a teacher- centred pedagogy which is in direct contrast to the child-centred learning environment in nursery (Cassidy, 2005).

\section{Theoretical Frame}

The origins of the move towards an active learning approach in the infant classroom are somewhat unclear and there is little explicit reference to research on active learning in an early years context. There is however a substantial body of literature about the benefits of moving away from passive styles of learning such as lecture or teacher exposition to ways of learning that require active participation to enable the development of techniques and skills. (Bonwell and Eison,1991; Mayer,2004; Prince, 2004). Indeed in the Higher Education sector, in particular within medicine, there is an acceptance of the benefits of collaborative or cooperative experiential learning set in a meaningful context for the students. The scope for alternative interpretations of active learning along with our earlier findings that teachers and children have different perspectives on what is engaging in the classroom (Stephen et al,2008) made this development and implementation of an active learning approach in the infant classroom an appropriate issue to research. Current interpretations of active learning have a focus on the teacher as a facilitator and scaffolder rather than a didactic instructor, with children having choices in what they do and when they do it. This move towards an active learning approach in the infant classroom has been identified by the Scottish Executive (2007) as a more play based curriculum.

Recent research provides evidence that play develops children's content knowledge across the curriculum and enhances the development of social skills, competencies and disposition to learn. (Wood and Attfield, 2005). For these reasons it is considered to be an integral element 
of a high quality provision for young children (Siraj-Blatchford and Sylva, 2004) and the amount of time a teacher allocates to play gives 'messages' about its importance and value. These authors locate play within a Vygotskian model of scaffolding with the teacher focussing attention on specific elements of the play and through appropriate feedback encouraging children's enquiry.

Guidance issued under the Curriculum for Excellence, Scottish Executive (2007) states that Active learning is learning which engages and challenges children's thinking using real-life and imaginary situations. It takes full advantage of the opportunities presented by spontaneous and planned, purposeful play; investigating and exploring; events and life experiences; focused learning and teaching (Scottish Executive, 2007:5).

It also acknowledges that adult support should be given when necessary through sensitive intervention to extend learning. The Welsh Assembly Government also links active learning and play and describes the early years curriculum as play/active learning, defining it as

... children being active and involved in their learning. Children learn best through first-hand experiences.... The purpose of play/active learning is that it motivates, stimulates and supports children in their development of skills, concepts, language acquisition/communication skills and concentration. It also provides opportunities for children to develop positive attitudes and to demonstrate awareness/use of recent learning, skills and competencies, and to consolidate learning. (Welsh Assembly Government, 2008:54) 
Bodrova and Leong (2007) highlight the important role that play has in preparing children for the rigours of formal schooling and suggest that the current dilemma facing early childhood teachers is whether to focus on teaching academic skills or to promote and encourage developmentally appropriate activities for children. They identify that one of the important elements of play is the restraint placed upon the activity by the children themselves in the form of rules that the child must follow in order to play 'properly'. This notion of selfregulation was considered by Vygotsky (1978) as a way in which young children learned to follow rules and control their emotions rather than acting on impulse and suggests that if children are able to do this they are likely to be able to master the academic skills required in formal schooling.

However, while play is considered to be an important element in an early years environment many primary teachers are unsure of how to plan for such a curriculum (Moyles et al, 2002). Wood and Attfield (2005) suggest that an approach based on both curriculum-generated play to support the development of specific skills and knowledge and a play-generated curriculum based on teachers responding to the interests of the children is the best approach to curricular planning. This type of responsive planning is common in the nursery environment in Scotland but has been less so in the formal school sector and is not supported by many of the planning frameworks commonly used in primary schools.

Walsh et al. (2006) undertook a study which explored an appropriate curriculum for 4-5 year old children in Northern Ireland, where children commence formal schooling in the school year of their fifth birthday. They compared a play-based curriculum with a more formal, traditional curricular approach. Their findings indicated that the play based curriculum 
(Enriched Curriculum) offered 4-5 year old children a higher-quality learning experience than that of the more traditional formal curriculum.

Our research project aimed to explore the difficulty facing Scottish early childhood teachers when today's young children seldom have the opportunity to engage in what Vygotsky calls "fully developed mature make believe play" (1978) where children are involved in “imaginary situations” with their peers. Broadhead (2004) describes children’s play as becoming more complex as they become more skilled and develop their play into a more organised and structured process. Sutton-Smith (1997) highlights that as children play they develop play skills which enable them to interact with other children thus improving their social and cognitive skills. Children become more adept at creating rules and subsequently develop more awareness of outcomes as well as processes. Sawyer (1997) suggests that pretend play with peers contributes to children's development and allows them to understand the thoughts and feelings of others; he describes this ability as metacognition or theories of mind (Sawyer, 1997: 23)

The move towards active learning poses a challenge for the early years teacher when the requirement for accountability and formal assessment in the school setting differs from the less formal assessment methodology in the nursery setting which has historically been integrated into learning and teaching interactions (Curriculum Framework 3-5, 1999). In the pre-school establishment the child initiates action and the practitioners respond and join in a child centred and responsive manner. Van Oers (2003) states that 
There is ample reason to consider the learning processes in the play-based curriculum as effective learning, though it must be admitted that more research is needed to substantiate this claim further (Van Oers, 2003:23).

Reviewing the literature on an early years pedagogy based on play and active learning leads to the conclusion that the role of the teacher in supporting children's engagement with learning is of crucial importance and that for many teachers the prospect of children learning through play is problematic. Bennett et al’s (1997) study of teachers' perceptions of play in nine reception classes demonstrated that although teachers were committed to integrating play into the curriculum there were difficulties in measuring progression. They also identified that the teachers found problems in supporting the children's learning and increasing their own knowledge of the value of some play contexts. One of the main findings of the study was that teachers need to be more interactive and engage with the learners. Pramling Samuelson and Johansson (2006) highlight that play and learning have often been viewed as separate entities. However, they suggest that the role of the teacher is to integrate both dimensions, providing both support and challenge for learners. The present study explores the ways that early years teachers are attempting to shift their practice towards a more interactive and engaging pedagogy, and how extensive such efforts are.

\section{Methods}


The research took the form of a small-scale exploratory study within two Scottish local authorities (LA) already supporting the shift to active learning. The research questions explored within this article focus on the form of active learning in the first year of primary school (P1); what active learning meant to teachers and evidence of the engagement of the children in active learning situations.

The researchers focussed on six classrooms and data was collected through a variety of methods. Although there was a change of teacher in one of the schools the data collected from this classroom has been included in the finding as the pedagogical approach did not alter. Semi-structured, focussed interviews were conducted with class teachers, and each teacher was invited to share data which they gathered - e.g. their own records of classroom observations, daily plans and experiences, extracts from children's profiles and photographs or notes recording particular classroom events. All interviews were digitally audio taped and transcribed. We asked the teachers a variety of questions about the adaptation that a change to active learning necessitates; their evaluation of the outcomes in their own practice; their conception of their role and the support active learning offers young learners.

Systematic and targeted observations were conducted in each of the classrooms noting teachers' and children's actions. Each classroom was observed on 4 separate occasions throughout the academic year. On each of these occasions the classroom setting was scanned every 10 minutes throughout the day and the observer noted the form of classroom organisation, the actions of the teacher, the actions of the children and the level of engagement of the children. 
Timed observations of target children (Sylva et al 1980) were also carried out between the class scans. All target children were selected randomly in each setting with an equal gender balance and on most occasions each target child was subject to 3 periods of observation during the session. Each of the target child observations lasted for approximately five minutes, focussing on what the child was doing, who was with her/him, interactions with other children or adults, behavioural indicators of pleasure or satisfaction and a judgement was made by the researcher about the level of the child's engagement using five categories based on the Leuven Involvement Scale (Laevers 1994). These were (1) intensely engaged, (2)

busy, (3) intermittent engagement, (4) passive and (5) not engaged. Judgements about engagement were made on the basis of observable bodily indications such as eye contact with a speaker, turning away or fidgeting, being alert or disinterested. The categorisation of the actions was subject to inter-rater reliability checks with a very high degree of agreement reached on the most frequently observed actions. Although these are relatively high-inference judgements we ensured satisfactory inter-rater reliability before commencing the data collection and drew on earlier experience of using behavioural indicators of children's affective states (e.g. Stephen 2003).

\section{The classroom environment and structure}

The classrooms varied in layout but were arranged to promote play based learning. All classes made use of the classroom and adjacent spaces for activities and small group sessions. In each case these additional spaces were shared with other classes, requiring adherence to an agreed timetable. Two classrooms were in the same school and located in an infant base with individual classrooms for each teacher and a shared open plan activity area; requiring careful planning from each teacher. In one school the classroom was situated in an open plan infant 
area causing the teacher some concerns regarding the lack of walls for display purposes and the high level of noise. Within this school access to additional space was particularly limited as the class had to share a small room with others in that part of the school. Each classroom had an area where the whole class gathered for teacher instruction and directions about the structure of the day, singing and story time. In most of the classrooms tables and chairs took up much of the space so resources for individual or group activities were brought out of storage when required. In one of the classrooms there was a large interactive Smartboard which was usually used by children in turn during whole class, teacher-directed sessions. In another school the Smartboard was situated in an adjacent room and used by both teacher and children during small group activities.

The routine in most of the classrooms was similar: there was generally a period of whole class activity with the teacher dealing with routine administration, phonics, number work (what could be considered to be a more traditional approach but with more active involvement from the children) and then periods of play based activities in small groups. One of the classrooms differed in that the children moved freely between work stations and decided on their tasks for the day, in the other classrooms the children were directed to particular activities and moved around them in sequence.

\section{Findings:}

\section{Teacher views on the benefits of active learning.}

All six teachers were positive about the promotion of active learning in their P1 classrooms; however, it should be noted that all were based in schools which had been identified by their local authority managers as suitable for inclusion in the study. All of the interviewees 
believed active learning promoted a positive, enthusiastic attitude to learning and encouraged independence and confidence in children. Most teachers stated that they felt that it was inclusive as it made learning accessible to all of the children, regardless of their ability. They believed that the children were more engaged in learning, learned at a faster rate, and were encouraged to collaborate and integrate as a group. Several teachers also noted that it was a better experience for the teacher as it gave them more time with individual children. For example Teacher B stated :

I know the class so well already because of the way managing it - can spend time talking to them, identifying next steps. Able to give lots of oral feedback - give quality feedback to children.

\section{Teacher views on the challenges of active learning.}

One of the concerns highlighted by the teachers was gathering evidence of children's learning: moving away from workbook and worksheet resulted in challenges in terms of assessment. They had, however, developed the use of other methods and sources including the compilation of journals of children's learning.

[We] take photos and make up big books kept in class. We take photos of work on the whiteboards and record discussion at plenary sessions. (Teacher C).

Teachers also noted that they had to adjust their thinking about the way in which the classroom was organised One of the aims of the move to active learning was...

to take the best of nursery practice into P1- keep the children independent and active in their own learning (School Head E). 
[We] looked at the children in primary and noted how 3-5 year olds that had been independent (setting things up, clearing away, doing activities for themselves) now in school were asking to have their pencils sharpened! Were concerned about what was being taken away from them and what to do in P1 in school it is set up so that children are waiting for the teacher - just seemed very un-natural for children to be sitting waiting for a teacher to do things. (Teacher E).

However, teachers also noted that they had to adjust their thinking towards the way the day and the activities were structured. Several of the teachers stated that they promoted an active learning approach as they felt that it allowed them to spend more time with individual children and to scaffold and guide the learning.

\section{Observations of active learning in class}

The teachers' choice of organisational structures reflected different ideas about what active learning actually entailed. In three of the observed classes teachers had carefully timetabled some activities in an open area beside the classrooms and this activity time came after class teaching and routine administration. The children rotated between activities within the classroom and the open area and worked independently in the open area on most occasions, without direct input from the teacher. The children were often supported in these situations by classroom assistants and/ or parent helpers. The observers categorised the classroom activity into two main categories: whole class activity (more traditional approach although with more active participation) and small group activity (active learning/ play based approach) and observed the children's actions. 
During whole class sessions, the children were engaged in a variety of actions. The observers noted the following: the children listened; looked; chanted responses; gave answers; counted, added; measured; made number stories; identified words, letters, sound and rhymes; rehearsed tasks/ skills; responded to behaviour rules; used the interactive Smartboard; assembled; tidied; waited, and they also demonstrated disengagement. Signs of disengagement included actions such as restless, aimless or inattentive behaviour; wandering about or abandoning an activity or group; twisting hair or clothing; yawning; quarrelling with others. There was a wide range of activities and tasks on offer throughout the session and children were directed to these after whole class teaching/ routine administration took place. These activities included role play, construction, listening post, sand, train set, number tasks in pairs, story writing with teacher, computer games, painting, reading with teacher, language tasks and workbook pages to complete individually. See figure 1.

Insert figure 1 here.

The children demonstrated a variety of actions during the second category (active learning/ play based) group activities. They followed instructions; gave answers; negotiated roles with others; ordered words or numbers; copied patterns and drew pictures; listened to stories or songs; used the computer or Smartboard; practised reading; did jigsaw puzzles; built with construction materials; measured, counted, added up; lined up, cleared up, moved round. There was a marked difference in signs of disengagement between the different contexts i.e. whole class teaching and small group experiences and between different classrooms. See figure 2

Insert Figure 2 here. 
During the more traditional whole class sessions there were many more signs of disengagement compared with the more active learning sessions. This is not surprising given the larger numbers of children in whole class situations and the corresponding ratio of children to teacher reducing the opportunity for teacher support to enable children to stay on task. Children also spent a larger percentage of time in transition during the whole class sessions compared with the small group activities.

All of the teachers planned a mixture of whole class and small group experiences. In all of the classrooms there was a difference in the role of the teachers between whole class and small group activity. Observers noted much higher levels of scaffolding during small group experiences with half of the teachers spending approximately one third of their time in this way compared with whole class experiences. Although the teachers described the pedagogy within the classroom as 'active' play based learning there were episodes in each session when there was whole class teaching, often involving the children sitting for lengthy periods of time. Within these periods the teachers' role was proximal. They managed behaviour and transitions; explained the class schedule; directed children's actions; instructed; praised; led discussions; scaffolded children's thinking and actions and asked questions. The children were not engaged in play during these whole class experiences; however in some classrooms the approach was active, with children often involved in physical responses to number work or phonics. See Figure 3.

\section{Insert figure 3 here.}

The teachers also directed children to activities in small groups. However, these activities did not necessarily require children to work together in the group or allow for any degree of 
personalisation or choice. Only one class teacher gave children the opportunity to choose what to do and when to do it. The children in the other classrooms had their day carefully structured and had no autonomy in deciding either the order of their activities or the duration of the learning experience. The children had little opportunity for autonomy as they were grouped for tasks and could only move on to the next task at the direction of the teacher. See Figure 4.

\section{Insert figure 4 here}

Levels of teacher support varied. The teachers in the study demonstrated both the types of activity identified by Fisher (1996: 55). The teacher- intensive actions took place generally within whole class teaching and the teacher-initiated actions took place when the children were involved in small group tasks. However, there was little evidence of child-initiated action (children investigating and engaging in tasks which have meaning for them) which Fisher describes as the third side of a triangle representing the balance of classroom activities. There was little evidence of child initiated tasks in either whole class situations or in small group tasks. The amount of time children were identified as engaging in positive peer interaction was variable - in two of the classes there was no observed peer interaction at all. However $10 \%$ of children's actions were recorded in this category during small group activity in classroom E , and 13\% during whole class activity in classroom C.(See Figures 1 \& 2).

\section{Discussion}


The move towards a more play based active curriculum in Scotland has been met with enthusiasm from many teachers. However, there are different understandings of the purposes and structure of such a pedagogy. The need for a pedagogy based on active learning, incorporating features of play, in the early stages of formal education presents a challenge for some teachers as it requires them to create an appropriate learning context which allows them to follow children's interests and build upon prior knowledge. This type of approach presents difficulties for those teachers who are used to a more rigid curricular structure and who have concerns over accountability and attainment targets. Goouch, (2008) writing about teachers working within the constraints of the English National Curriculum, suggests that teachers in the early years classroom who spend long periods of time with young children should engage with them and help them "find meaning and sense in their play narratives" However, she states that the teacher must trust that cognitive development will occur without the need to 'hijack’ the situation. (Goouch, 2008:101).

The concerns of the teachers in this study over gathering evidence of children's work and learning were met in some way by the documentation of children's work, based on the Reggio Emilia approach, a method of recording children’s involvement and learning using photographs, narrative and children’s drawings (Malaguzzi, 1995). Using this approach, teachers can review and revisit children's work at a later date; children, other professionals and parents also have access to the material. The assessment of individual children was carried out in some of the classrooms through the use of Learning Stories (Carr, 2001), commonplace in many nursery settings. Carr suggests that assessment should be based on the perspective of the learner, and that the narrative approach used in Learning Stories reflects the learning better than performance indicators (Carr, 2001: 92-5). 
What must be clear from all this, is that the evaluation of effective learning and teaching cannot be reduced to a simple test or even a collection of individual test score (however robust these tests may be). At best tests demonstrate how well the pupils can make these (Van Oers, 2003:23).

Fisher (1996) describes the 'negotiated classroom' and discusses the importance of the teacher planning for a range of tasks, both teacher initiated and child initiated, and of children being free to move on to the next task when they have successfully completed the previous one. It is interesting to note that there was very little evidence of child initiated tasks in any of the observed classrooms in the study and minimal evidence of peer interaction.

One of the main difficulties with trying to introduce a way of working more in line with the experiences offered in the nursery sector is the reduced ratio of adults to children. In the nursery school environment the adult/child ratio is 1 adult per 10 children, while in the primary classrooms observed in this study the adult/child ratio was 1 adult per 25 children, supported in some classrooms by a classroom assistant for periods of time. Teachers interviewed during the study stated that learning in the primary school environment can be less responsive to individual children's interests and needs. Activities and resources are supplied by the adults for use in the nursery playroom, but the children are able to choose when to engage with specific activities and the equipment and tasks are much more likely to afford open-ended play or exploration. This was not an option for the teachers in this study as there are practical challenges in terms of planning, monitoring and classroom management in the primary school context which require a shift in pedagogy that goes beyond the bounds of individual teachers and their classroom interactions. 


\section{Conclusion}

The evidence reported above suggests that although the teachers in the study were enthusiastic, they had different understandings of the purposes and benefits of the active learning approach. The observation data indicate that teachers possibly held different conceptions of active learning, and found it difficult to reconcile the idea of active learning with the practical pedagogical realities such as large numbers of children in the primary classroom compared to the much smaller child / adult ratio in the nursery setting. The data suggests that the shift from a more traditional school pedagogy, concerned with targets and outcomes, to a pedagogy based on the responsive, interactive nursery ethos, is one that requires additional resources and training to support the demands placed upon teachers. This issue was highlighted by the Scottish Executive (2004):

\footnotetext{
All staff have a role as leaders of learning in helping to bring about improvement for children. Many staff will already be practising active learning approaches while others may need to adjust their practice to meet children’s needs better...Many staff will require opportunities and support to develop their methodology and thinking in relation to active learning (Scottish Executive, 2004:4).
}

This is a small-scale qualitative study; therefore most conclusions must be tentative.

Several questions have been raised by this research into active learning. One important aspect to be considered is in defining active learning - are 'activities' active or is the term related to intellectual activity? Wood and Attfield (1996) contend that active learning is learning which 
is initiated by the child rather than by the teacher. This view is readily accepted by nursery providers as it matches their understanding of how young children learn. However, it appears that this view may not be as widely held within the school sector, where teachers remain concerned with targets and outcomes. Goouch (2008) however provides an optimistic prognosis for teachers in the early years:

perhaps there is hope that, since teachers in the early years spend many hours a day in classrooms with young children, they will become susceptible to their collaborative needs and sufficiently seduced by children's desires to find meaning and sense in their play narratives to co-join with them in their endeavours (Goouch, 2008:101)

Additional research is also required to study the progression of the children who were introduced to this new pedagogy in the early years of primary school and who are moving through the primary school being taught by teachers who may not have had the experience of planning for an interactive play based curriculum either during their initial teacher education or their continuous professional development programme.

References:

Bennett, N., Wood, E. \& Rogers, S. (1997). Teaching Through Play: Teachers’'Thinking and Classroom Practice. Buckingham: Open University Press. 
Bodrova, E. \& Leong. D. J. (2007). Playing for academic skills. Children in Europe, Vygotsky Issue 2007, 10-11

Bonwell, C.C. and Eison, J.A. (1991) Active Learning: Creating Excitement in the Classroom. ASHEERIC Higher Education Report No 1 (Washington DC, George Washington University).

Carr, M. (2001). Assessment in Early Childhood Settings: Learning Stories. London: Paul Chapman Publishing.

Cassidy, M. (2005). 'They do it anyway': a study of Primary 1 teachers' perceptions of children's transition into primary education. Early Years, 25:2, 143-153.

David. T., Goouch, K., Powell, S. \& Abbott. L. (2003). Birth to Three Matters: A Review of the Literature compiled to inform The Framework to Support Children in their Earliest Years: London: Department for Education and Skills. 
Fisher, J. (2002). Starting From the Child? Teaching and learning from 3-8 ( $2^{\text {nd }}$ edition). Buckingham: Open University Press.

Goouch, K. (2008) Understanding playful pedagogies, play narratives and play spaces, Early Years, 28:1, 93-102

Laevers, F. (1994). (Ed.) Defining and assessing quality in early childhood education. Belgium: Laevers University Press.

Mayer, R. (2004) Should there be a three-strikes rule against pure discovery learning? American Psychologist, 59 (11), 14-19.

Malaguzzi, L. (1995) History, ideas and basic philosophy: an interview with Lella Gandini, in: C. Edwards, L. Gandini \& G. Forman (Eds) The Hundred Languages of Children: The Reggio Emilia approach to early childhood education. pp.41-89 Greenwich, Conn: Ablex

Moyles, J. (1995). Just Playing? The Role and Status of Play in Early Childhood Education. Milton Keynes: Open University Press. 
Moyles, J., Adams, S. \& Musgrove, A. (2002). Study of pedagogical effectiveness in early learning (SPEEL) Research Report No 363, London: Department for Education and Skills

Pramling Samuelsson. I. \& Johansson, E. (2006) Play and Learning- inseparable dimensions in preschool practice. Early Child Development and Care Vol. 176, No 1, January 2006, pp47-65

Prince, M. (2004) Does Active Learning Work? A Review of the Research. Journal of Engineering Education, 9 (3), 223-231.

Scottish Consultative Council on the Curriculum. (1999) A curriculum framework for children 3 to 5; Great Britain. Scottish Office.

Scottish Executive (2004) A Curriculum for Excellence. Edinburgh.

Scottish Executive (2004). A Curriculum for Excellence. Edinburgh. Scottish Executive http:// www.scotland.gov.uk/Publications/2004/11/20178/45863 [accessed 17.4.2009] 
Scottish Executive (2007) A Curriculum for Excellence, Building the Curriculum (2): Active Learning in the Early Years. Edinburgh: Scottish Executive.

http://www.ltscotland.org.uk/curriculumforexcellence/publications/Buildingthecurriculum2/in dex.asp [accessed 17.4.2009]

Sawyer, R.K. (1997) Pretend Play as Improvisation. Conversation in the Preschool Classroom. Mahwah: N.J.: Lawrence Erlbaum Associates.

Siraj-Blatchford, I. \& Sylva, K. (2004). Researching Pedagogy in English Pre-Schools. British Educational Research Journal, 30 (5), 713-730.

Stephen, C. (2003) What makes All-day Provision Satisfactory for 3- and 4-Year Olds? Early Child Development and Care, 173 (6), 577-588.

Stephen, C., Cope, P., Oberski, I. \& Shand, P. (2008). 'They should try to find out what the children like': Exploring engagement in learning. Scottish Educational Review, 40, 2, 17-28.

Stephen, C., Cope, P., Oberski, I. \& Shand, P. (2009). Turned on to Learning 1. AERS Research Briefing Paper No 7. Edinburgh: The University of Edinburgh. 
Stephen, C., Ellis, J. \& Martlew, J. (2009) Turned on to Learning 2. Active Learning in Primary One. AERS Research Briefing Paper No 8. Edinburgh: The University of Edinburgh.

Sutton-Smith, B. (1997) The Ambiguity of Play. Cambridge: MASS: Harvard University Press

Sylva, K., Roy, C. \& Painter, M. (1980): Child Watching at Play-Group and Nursery School. Grant McIntyre.

van Huizen, P., van Oers, B. \& Wubbels, T. (2005). A Vygotskian perspective on teacher education, Journal of Curriculum Studies, 37:3, 267-290.

van Oers, B. (2003). Learning resources in the context of play. Promoting effective learning in early childhood', European Early Childhood Education Research Journal, 11:1, 7- 26.

Vygotsky, L.S. (1978) Mind in Society: The Development of Higher Psychological Processes. Cambridge, MA: Harvard University Press.

Walsh, G. Sproule, L. McGuinness,C ;Trew,K., Rafferty,H ., Sheehy,N (2006) An appropriate curriculum for 4-5-year-old children in Northern Ireland: comparing play-based 
and formal approaches Early Years: An International Journal of Research and Development, 26, ( 2) pp. 201-221.

Welsh Assembly Government (2008) Play/Active Learning - Overview for 3 to 7-year olds. Available online at

http://new.wales.gov.uk/topics/educationandskills/policy_strategy_and_planning/104009wag/ foundation_phase/foundationphasepractitioners/playactive/;jsessionid=LGk4LcWSfJprnyxLg 2PqHlcT2Vbp1l6T8thwQTGHJSgQvQq4N1yp!686978193?lang=en\&ts=1 accessed $1^{\text {st }}$ June 2010

Wood, E. and Attfield, J. (2005) Play, learning and the early childhood curriculum (2nd edn), London: Paul Chapman.

${ }^{1}$ The Applied Educational Research Scheme was a five-year programme of research funded by the Scottish Executive Education Department and the Scottish Funding Council from 2004 to 2009, which aimed to build educational research capacity in Scotland and to harness that capacity to carry out high-quality research relevant to the Scottish National Priorities in Education.

Figure 1: Summary Children's Behaviour and Actions: Whole Class

\begin{tabular}{|l|l|l|l|c|c|c|}
\hline & \multicolumn{3}{|l|}{ Classrooms \% of total observations in each setting } \\
\hline Child actions & Class A & Class B & Class C & Class D & Class E & Class F \\
\hline C1 Obeying Behaviour Rules & 14 & 12.5 & 5 & 0 & 3 & 10 \\
\hline C2 Waiting/ In Transition & 17 & 22 & 5 & 3 & 3 & 8 \\
\hline C3 Waiting for T's attention & 0 & 3 & 0 & 0 & 0 & 2 \\
\hline C4 Responding to T led activity 1-1 & 7 & 16 & 18 & 21 & 24 & 23 \\
\hline C5 Responding to T led activity Joint & 7 & 12.5 & 10 & 25 & 14 & 6 \\
\hline C6 Responding/ physical actions & 3 & 0 & 10. & 12 & 0 & 14 \\
\hline C7 Individual task response & 0 & 0 & 13 & 9 & 0 & 2 \\
\hline C8 Contributing to T led discussion & 7 & 0 & 3 & 3 & 7 & 6 \\
\hline C9 Listening to T Instructions & 17 & 12.5 & 2 & 12 & 14 & 8 \\
\hline C10 Signs of Disengagement & $\mathbf{1 4}$ & $\mathbf{9}$ & $\mathbf{1 8}$ & $\mathbf{6}$ & $\mathbf{2 4}$ & $\mathbf{1 5}$ \\
\hline C11 Routine Tasks e.g. tidying & 14 & 12.5 & 3 & 6 & 3 & 6 \\
\hline C12 Positive Peer Interaction & $\mathbf{0}$ & $\mathbf{0}$ & $\mathbf{1 3}$ & $\mathbf{0}$ & $\mathbf{0}$ & $\mathbf{0}$ \\
\hline
\end{tabular}




\begin{tabular}{|l|l|l|l|l|l|l|}
\hline C13 Open Ended Activities e.g. sand, painting & 0 & 0 & 0 & 3 & 4 & 0 \\
\hline C14 Directed Activities e.g. matching game, computer & 0 & 0 & 0 & 0 & 4 & 0 \\
\hline
\end{tabular}

Figure 2: Summary Children's Behaviour and Actions: Groups/Distributed Class

\begin{tabular}{|l|l|l|l|l|l|l|}
\hline & \multicolumn{3}{|l|}{ Classrooms \%of total observations in each setting } \\
\hline Child actions & Class A & Class B & Class C & Class D & Class E & Class F \\
\hline C1 Obeying Behaviour Rules & 0 & 0 & 1 & 0 & 0 & 2 \\
\hline C2 Waiting/ In Transition & 1 & 2 & 3 & 6 & 5 & 9 \\
\hline C3 Waiting for T's attention & 0 & 0 & 0 & 3 & 0 & 3.5 \\
\hline C4 Responding to T led activity 1-1 & 0 & 0 & 3 & 0 & 0 & 12 \\
\hline C5 Responding to T led activity Joint & 0 & 4 & 36 & 0 & 0 & 2 \\
\hline C6 Responding/ physical actions & 1 & 0 & 5.5 & 0 & 0 & 0 \\
\hline C7 Individual task response & 18 & 25 & 12 & 32 & 22 & 21 \\
\hline C8 Contributing to T led discussion & 1 & 0 & 1 & 12 & 2 & 0 \\
\hline C9 Listening to T Instructions & 2 & 0 & 3 & 3 & 2 & 3.5 \\
\hline C10 Signs of Disengagement & $\mathbf{1}$ & $\mathbf{2}$ & $\mathbf{1 1}$ & $\mathbf{3}$ & $\mathbf{5}$ & $\mathbf{1 2}$ \\
\hline C11 Routine Tasks e.g. tidying & 2 & 0 & 0 & 6 & 12 & 3.5 \\
\hline C12 Positive Peer Interaction & $\mathbf{5}$ & $\mathbf{0}$ & $\mathbf{1}$ & $\mathbf{0}$ & $\mathbf{1 0}$ & $\mathbf{2}$ \\
\hline C13 Open Ended Activities e.g. sand, painting & 34 & 31 & 5.5 & 9 & 17 & 12 \\
\hline C14 Directed Activities e.g. matching game, computer & 35 & 36 & 18 & 26 & 25 & 17.5 \\
\hline
\end{tabular}


Figure 3: Actions when teacher leads whole class activity.

\section{St Roch (pseudonym) $28^{\text {th }}$ April 2008}

9.20. Whole class (24 children) on carpet in front of story board stand. $1 / 24$ at edge of group looking under table. Teacher reads big story book and stops to demonstrate jiving. Teacher moving to actions in story and instructs one child to play guitar like character in story. Children listening to story and begin copying Teacher’s dancing. They sit down and listen as 1 child plays guitar.

9.30. Whole class on carpet in front of story board stand. 4/24 talking at back of room. Question and Answer session as Teacher selects children to read words on cards and identify rhyming words. Teacher walks around whole group selecting children to read. Children are looking at rhyming cards in pairs, reading words when asked by Teacher. The group of 4 who are talking read cards as Teacher moves over to their area.

\section{South Side Primary (pseudonym) 16 January 2008}

11.00. Whole class ( 25 children) on carpet doing phonics. Teacher leads phonics exercise, holds up cards and directs a Question and Answer session. Children give oral responses - repeating after teacher, offering sounds for each card.

12.20. Whole class doing actions to Stinky Sam tape and then Alice the Camel activity. Teacher leads actions to tape; Student teacher also joins in actions. He leads Alice the Camel activity. Children are copying actions, laughing and calling out actions as well as doing them

\section{Figure 4: Actions during small group activity.}

\section{St Roch (pseudonym) $28^{\text {th }}$ April 2008 Children working in small groups. (24 children)}

\subsection{0am}

4 children at computer playing computer game.

4 at listening corner with headphones and story book, listening to story and following in words in book

7 at tables getting reading books, listening to teacher's instructions then moving to table to draw/ write.

9 in noisy/quiet room with classroom assistant. 5 playing game with classroom assistant in noisy/ quiet room and 4 playing word game without adult support.

10.40am Groups moving as directed by teacher.

4 playing computer game.

9 listening to teacher instructions re writing/drawing. Teacher checking writing/drawing. Stops to listen to children at computer watching/ supporting

2 on floor mat selecting letters to form words on magnetic board

5 playing game with classroom assistant in noisy/ quiet room and 4 playing word game on own in noisy/ quiet room.

\section{South Side Primary (pseudonym) 16 January 2008 Children working in small groups (25 children)}

11.10am. Children moving to group work - 4 groups

1 group with teacher doing whiteboard phonics work

1 group with student teacher doing word game

1 group with classroom assistant doing letter game

1 group independent writing in jotters

11.40am. as above

11.50am. All groups moving around to alternative task as directed by teacher 
